\title{
THE INFLUENCE OF DIGITALIS ON THE DIFFERENT PHASES OF THE HEART-BEAT, PARTICULARLY AS REGARDS THE INTRACARDIAC PRESSURE
}

\author{
BY I. HARRIS \\ (From the Cardio-Therapcutic Department, David Lewis Northern Hospital)
}

With Plates 2 and 3

IN this paper an attempt is made to study the influence of digitalis on the different phases of the heart-beat, particularly as regards the intracardiac pressure. There is no need for me to enter into the controversy as to whether digitalis acts directly on the heart-muscle or on the inhibitory apparatus. It is necessary, however, in order to appreciate fully the effect of digitalis on the human heart, to keep before one's mind one or two simple facts culled from experimental pharmacology. ${ }^{1}$

There is hardly any doubt that experiments on animals have demonstrated that digitalis has a double action, with effects which are more or less opposed to each other.

In so far as it acts on the inhibitory apparatus, it prolongs both diastole and systole, and the heart output is actually diminished; while its direct action on the cardiac muscle shortens both systole and diastole. The contraction of the heart becomes more powerful and the output of the ventricle greater.

The method employed in this observation consists simply in the taking of an electro-cardiogram before and after the administration of digitalis. The drug was administered per os in the form of tincture. The observation was made chiefly on out-patients, and also on a number of in-lying cases.

The ventricular systole was determined by the ventricular complex of the electro-cardiogram. According to Lewis (2) the earliest sign of contraction in the ventricle occurs in the commencement of $R$, and usually during the upstroke. In order to obtain a more stable point from which to begin the measurements, I have taken the junction where the horizontal line meets $R$ or $Q$ as the commencement of the systole, and the place where $T$ passes into the horizontal line as the end of the systole. This slight disparity between the actual commencement of the

[Q. J. M., Oct., rgrg.] 
systole and the beginning of $R$ is of no great consequence in measurements taken solely for purposes of comparison.

As regards the influence of digitalis on the pulse frequency, three distinct stages are discernible. 1. Digitalis diminishes considerably the pulse-rate. 2. The pulse-rate remains about the same as before the administration of the drug. 3. Digitalis greatly accelerates the pulse frequency. A typical action of digitalis on the human heart, if the drug is continued for long, is to start with stage 1 , pass through stage 2 , and finally end in stage 3 .

While the retarding effect of digitalis on the pulse is not constant, it invariably accelerates the pulse provided that a sufficient quantity of digitalis is given long enough. It depends on the condition of the heart-muscle what amount of digitalis is necessary to effect a translation of the heart from stage 2 to stage 3. Case No. 3, a case of chronic myocarditis, has reacted to 5 minims of digitalis thrice daily for a week by a considerable fall of the pulserate. The continuation of larger doses of digitalis for another week had the effect of greatly accelerating the beat. In other cases a large dose of digitalis may be given for many weeks without producing a great acceleration in the pulse-rate.

The effect of digitalis on different phases of the heart-beat is variable and depends to a large extent on the pulse-rate. There is no necessity for me to deal with the auricular phase, which has already received an exhaustive treatment from many observers. The systole is remarkable for its stability so far as length is concerned. Whatever the condition of the cardiac,action may be, there is very little difference in the duration of the systole in different individuals. I have examined some hundreds of cardiograms, and if we except heart-failure, gross lesions of the myocardium, and the influence of drugs, the duration in almost all cases varies between 0.32 and 0.36 of a second. As a rule, it is nearer the first figure than the second. Very rarely it is below the first, in very few cases it exceeds the second figure. In stage 1 the systole is prolonged, although not to the same extent as the diastole (about $\frac{2}{25}$ of a second is a good average). In the second stage the systole is actually shorter than before the administration of digitalis, although the pulse-rate remains the same, and even when it is lessened. This is easier to demonstrate in cases where the duration of the systole before the administration of digitalis is relatively long.

In the third stage arising under the influence of digitalis the duration of the systole is still shorter. This shortening exceeds considerably the lower limit of variation found under normal circumstances in the human heart, and in the first two stages. The systole is shorter by more than one-half than it is prior to giving digitalis.

The diastole in the first stage is greatly, in the second stage slightly, increased, and in the third stage may become diminished to such an extent as to be actually shorter than the systole. Whilst thus the relative length of the diastole as compared with the systole is longer in stages 1 and 2 under digitalis, we find it may be actually shorter than the systole in the third stage. 


\section{Other Changes in the Electro-cardiogram produced by Digitalis.}

There is no need to refer to the $P R$ interval, to the coupled beats, and the different irregularities which are due to digitalis. These have been exhanstively dealt with by other writers. I will refer only to two alterations in the character of the electro-cardiogram which digitalis produces. The one is digitalis depression, the other is an alteration in the $T$-wave.

'The digitalis depression has been described by me in a short note published in the Lancet (4). It is a curious depression in the electro-cardiograms between $R^{1}$ and $T$. In the average of my cases, one drachm of digitalis per diem has produced this phenomenon, although in one case the depression was already marked after five minims of digitalis thrice daily for a week. Here again it depends on the condition of the myocardium which doses are required to produce this phenomenon. In one case, just after acute rheumatism, 5 minims of digitalis thrice daily were sufficient to produce this phenomenon. A few months later, when the state of the patient's heart was considerably improved, it took 20 minims twice daily for two weeks to produce the same depression. The depression is more pronounced, and it takes a smaller quantity of digitalis to produce it, in old age. But an important fact in connexion with the depression is that $I$ have never seen it in stage 1 under digitalis. It invariably makes its appearance either when the pulse-rate has not slowed down at all under the administration of digitalis, or when it has done so to a moderate extent only. I have never seen this depression where the heart is in the third stage. The depression remains noticeable till about three weeks after the discontinuance of the drug. Atropin has no influence on its duration. When the depression is marked the patient usually complains of difficulty in breathing, faintness, \&c.

$T$-wave. Cohn (3) has already described an alteration of the $T$-wave under the influence of digitalis which takes the form of an inversion. I have seen this inversion only in lead 1 , but the amplitude of $T$ in lead 2 is considerably diminished.

Strophanthus. I have never seen any strong reaction in the beart produced by this drug. I have never been able to observe a similar depression in the electro-cardiograms taken from patients under the influence of strophanthus, no matter how large the doses were. I have but rarely seen an alteration in the $T$-wave as a consequence of strophanthus treatment. However, as I have been in the habit of administering strophanthus per os, the contention of Cushny, that strophanthus given per os in aqueous solution is ineffective, may account for the poor result obtained.

1 It is suggested that a digitalis depression has something to do with inverted $T$. This is not so. Where $T$ is inverted it is well defined in shape and form, and its occurrence as regards time is the same as in normal $T$. The contrary is true. Digitalis depression often affects the shape of $T$-wave, so that only the part of it which is not affected remains normal. Where the depression is not much developed, so that it does not become necessary for it to encroach on the space of $T$, its independence is manifest. In the same manner the depression may also affect the shape of $R$. Finally, inverted $T$ and digitalis depression find their maximum development in different leads.

[O. .J. M., Oct., rg19.] 
Helleborein. Unlike other observers, I noticed a great slowing of the pulse produced by administration of this drug. This result may possibly be due to the fact that I have prescribed helleborein in large doses (one drachm of the liquor three times a day). I have never seen digitalis depression as a result of an administration of the drug. I find caffeine prolongs the systole, and both caffeine and camphor increase considerably the amplitude of the $T$-wave.

\section{Discussion.}

One of the most important features of uncomplicated heart-failure is the greatly accelerated pulse. Such a pulse differs from the normal pulse in that the relative durations of systole and diastole have undergone a profound change.

The diastole is often actually shorter than the systole. Let us consider for a moment the mechanism of heart-failure. The heart-muscle is unable to stand the strain of intracardiac pressure and gives way by dilatation. The diastole of the dilated heart is shorter than the normal diastole. This shortening of its duration implies that a smaller quantity of blood reaches the heart than in the normal condition. The result is that at the beginning of the systole there is less blood in the ventricle and the ventricular pressure is proportionately lessened. Clearly, the acceleration in the pulse-rate in this case should be looked upon as an adaptation of the organ to special circumstances, failing which the beart would be unable to accomplish the necessary amount of work. As the output at each beat is smaller than normally, the number of contractions must increase. Even so, the increase in the pulse-rate finally fails to make up for the smaller quantity of blood given out at each contraction, with the result that venous engorgement takes place. This is the cardiac condition in which digitalis is usually indicated.

To simplify matters, we shall leave out of consideration the tonic and sedative qualities of digitalis on the heart. If digitalis would simply lengthen the diastole without affecting in any way the systole the intracardiac pressure would be even higher than normally. Such a drug would hardly be indicated under the circumstances. Let us now look at the nature of the action of digitalis in its first stages. We know from experiment on animals that when digitalis slows the pulse-rate it acts on the inhibitory apparatus. We have seen what such action means: it prolongs not only the diastole, but also the systole, though the latter to a smaller extent. The systolic contraction is less powerful than it is before the beart-failure occurs. True, the diastole is longer, but we have reason to believe that the flow of blood to the heart takes place at a slower rate than normally. In addition, the slowing of the pulse-rate gives the heart so much more time to recuperate. Thus, whereas the intracardiac pressure in the first stage of digitalis is less and certainly not higher than normally, the heart action takes place under more favourable conditions. In the second stage of digitalis the slowing of the pulse-rate diminishes, and may even reach normal level. We know from animal experiment that this means a direct action of digitalis on the heart-muscle, and that under these circumstances the systolic contraction is more 
powerful and makes a greater demand on the heart-musele. We have seen also that the systole is actually shorter than in the normal condition. This means that a normal quantity of blood is driven out under a greater intracardiac pressure. . Thus the strain on the heart-muscle will be correspondingly greater. It is obvious also that the two diametrically opposed effects of digitalis might overbalance each other either way, not only when the pulse has reached the normal rate, but even before or after that. With the continued administration of digitalis its effect on the heart-muscle continues to increase. Then occurs what is usual whenever the heart-muscle is no longer able to stand the strain, viz. a great and sudden acceleration in the pulse-rate, the diastole becoming shorter than the systole. The ventricles contain only a relatively small quantity of blood at the time of contraction, with the result that the intracardiac pressure falls considerably. This is the third stage of digitalis action on the heart.

If the acceleration of the pulse-rate in these cases was due to the paralysis of the inhibitory apparatus, as is generally held to be the case, it would be difficult to understand why digitalis should so much more easily produce the acceleration of pulse in the myocardiac condition than in the normal heart.

So far as the digitalis depression is concerned, I regard it as a reaction of the heart, a response by dilatation to the rise of intracardiac pressure. This depression does not occur either in stage 1 or in stage 3 : in short, where there is no rise in blood-pressure. This is also in conformity with the fact that usually the patient is feeling unwell and the depression is marked. The fact, too, that in the diseased heart-muscle digitalis produces it more easily indicates that the intracardiac pressure has something to do with it. We have also seen that it is produced more easily and is generally more marked in old age, a time of life, as a correspondent in the Lancet (5) pointed out, when the heart is little adaptable to variations of intracardiac pressure. In connexion with digitalis, if we survey all the facts gathered clinically and experimentally, we shall easily come to the conclusion that it is a dangerous drug, which may not be prescribed indiscriminately, a fact fully appreciated in former times, but frequently sinned against by modern cardiologists. Irregularity, increase in the $P R$ interval, coupled beats, digitalis depression, inversion of $T$, are all pathological conditions which are doubtless harmful to the heart. Digitalis ought not to be pushed to such an extent as to produce these phenomena. Even in those cases where the digitalis treatment is most successful-in auricular fibrillation--it owes its effect to a quality which otherwise would not commend itself to us as a virtue. With few exceptions the administration of digitalis ought only to be continued as long as it produces an appreciable slowing of the pulse-rate.

I am indebted to the Medical Board of the Northern Hospital for permitting the use of material in connexion with this paper. 


\section{TABLE I.}

A girl of seventeen. Mitral regurgitation-compensation good-only slight amount of hypertrophy of left ventricle. No evidenee of myocardial trouble.

8.1.18.

\begin{tabular}{|c|c|c|c|c|c|}
\hline $\begin{array}{l}\text { Whole } \\
\text { Pulse in } \\
\text { Seconds. }\end{array}$ & $P-R$. & $R-T$ & $T$ & $P$ & Digitalis Depression. \\
\hline $\begin{array}{l}0.94 \\
\mathbf{0 . 8 4} \\
\mathbf{0 . 7 8} \\
\mathbf{0 . 8 2} \\
\mathbf{0 . 7 2} \\
0.74 \\
0.86\end{array}$ & $\begin{array}{l}0.16 \\
0.16 \\
0.16 \\
0.16 \\
0.16 \\
0.16 \\
0.16\end{array}$ & $\begin{array}{l}0.35 \\
0.4 \\
0 \cdot 36 \\
0.36 \\
0.36 \\
0.4 \\
0.36\end{array}$ & $\begin{array}{l}\text { L I. Inverted } \\
\text { L II. Slightly marked }\end{array}$ & $\begin{array}{l}\text { L } \quad \text { I. Inverted } \\
\text { L } \quad \text { II. Normal }\end{array}$ & $\begin{array}{l}\text { L I. Nil } \\
\text { L } \\
\text { II. Nil }\end{array}$ \\
\hline
\end{tabular}

15.1.18. Since 8.1.18 Digitalis $\mathfrak{a}$ ) $x$ thrice daily (t.d. s.).

0.72

0.70

$0.16 \quad 0.32$

L I. Inverted

L I. Inverted

L I. Absent

$\begin{array}{lll}0.86 & 0.2 & 0.32\end{array}$

0.76

$0.16 \quad 0.32$

L II. Well marked

L II. Normal

L II. Fairly marked

L III. Well marked

L III. Normal

L III. Fairly marked

22.1.18. Since 15.1.18 Digitalis $\mathfrak{O}) \times x v$ thrice daily (t. $d . s$.$) .$

\begin{tabular}{|c|c|c|c|c|c|}
\hline $\begin{array}{l}0.92 \\
0.84 \\
0.94\end{array}$ & $\begin{array}{l}0.2 \\
0.2 \\
0.2\end{array}$ & $\begin{array}{l}0.34 \\
0.32 \\
0\end{array}$ & L I. Inverted & L I. Inverted & L I. Absent \\
\hline & & 0.32 & $\begin{array}{l}\text { II. Not inverted, } \\
\text { but badly de } \\
\text { veloped }\end{array}$ & L II. Normal & L II. Well marked \\
\hline 24 & $\begin{array}{l}0.21 \\
0.2\end{array}$ & $\begin{array}{l}0 \cdot 34 \\
0.36\end{array}$ & L III. Present & L III. Normal & I III. Marked \\
\hline
\end{tabular}

5.2.18. Since 22.1.18 Digitalis $\mathfrak{M} \times \times v$ t. d. s. Since 29.1.18 Helleborein.

$\begin{array}{llllllll}\mathbf{1 . 1 4} & 0.22 & 0.34 & \text { L } & \text { I. Inverted } & \text { L } & \text { I. Inverted } & \text { L } \quad \text { I. Absent } \\ \mathbf{1 . 1 4} & 0.2 & 0.36 & & & & \\ 1.23 & 0.22 & 0.35 & \text { L } & \text { II. Normal } & \text { L } & \text { II. Normal } & \text { L II. Slightly marked } \\ 1.16 & 0.2 & 0.36 & & & \\ 1.12 & 0.2 & 0.36 & \text { L } \text { III. Normal } & \text { L III. Normal } & \text { L III. Present }\end{array}$

19.3.18. Since 12.3.18 Helleborein.

$\begin{array}{lll}0.78 & 0.22 & 0.34 \\ 1.20 & 0.22 & 0.32 \\ 1.08 & 0.2 & 0.36\end{array}$


TABLE II.

Robinson. Male, aged 52. A medium degree of arteriosclerosis of vessels and heartis able to do a normal day's work.

2.10.17.

\begin{tabular}{|c|c|c|c|c|c|}
\hline $\begin{array}{l}\text { Whole } \\
\text { Pulse in } \\
\text { Seconds. }\end{array}$ & $P-R$. & $R-T$ & $T$. & $P$. & Digitalis Depression. \\
\hline 0.7 & 0.2 & $\begin{array}{l}0.35 \\
0.34\end{array}$ & L I. Marked & L I. Normal & L I. Nil \\
\hline $\begin{array}{l}0.68 \\
0.68\end{array}$ & $\begin{array}{l}0.2 \\
0.2\end{array}$ & $\begin{array}{l}0.34 \\
0 \cdot 34\end{array}$ & I II. Marked & L II. Normal & L II. Nil \\
\hline 0.7 & $0 . \overline{2}$ & $0 \cdot 32$ & & & \\
\hline 0.7 & $0 \cdot 2$ & 0.32 & L III. Marked & I III. Normal & L III. Nil \\
\hline 0.68 & $0 \cdot 2$ & 0.34 & & & \\
\hline 0.68 & 0.22 & $0 \cdot 34$ & & & \\
\hline 0.66 & $0 \cdot 2$ & 0.32 & & & \\
\hline
\end{tabular}

9.10.17. Digitalis $\mathfrak{( n )} \times$ t.d. s. since 2.10 .17 .

\begin{tabular}{|c|c|c|c|c|c|}
\hline 0.70 & 0.2 & $0 \cdot 35$ & L I. Marked & L I. Inverted & L I. Nil \\
\hline 0.70 & $0 \cdot 2$ & 0.36 & & & \\
\hline 0.74 & 0.24 & $0 \cdot 36$ & L II. Marked & L II. Marked & I, II. $\mathbf{N}$ \\
\hline 0.74 & $0 \cdot 2$ & 0.34 & & & \\
\hline 0.70 & 0.22 & $0 \cdot 36$ & I III. Marked & L III. Marked & L III. 1 \\
\hline 0.82 & 0.2 & $0 \cdot 34$ & & & \\
\hline 0.82 & 0.2 & 0.36 & & & \\
\hline 0.74 & 0.2 & $0 \cdot 36$ & & & \\
\hline
\end{tabular}

16.10.17. Digitalis $\mathfrak{m} \times \mathbf{v}$ t.d.s. since 9.10 .17 .

\begin{tabular}{|c|c|c|c|c|c|}
\hline 0.82 & 0.24 & 0.33 & L I. Marked & 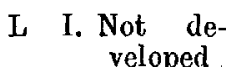 & I I. Well marked \\
\hline 0.80 & 0.24 & 0.33 & & & \\
\hline 0.78 & 0.24 & 0.33 & & & \\
\hline 0.80 & 0.24 & $0 \cdot 35$ & L II. Marked & I. II. Normal & L II. Well marked \\
\hline 0.80 & 0.24 & $0 \cdot 36$ & & L II Normel & I III Nat nrogant \\
\hline 0.80 & $0 \cdot 24$ & 0.35 & L ПII. Marked & L III. Normal & L III. Not present \\
\hline
\end{tabular}

6.11.17. Digitalis $\mathfrak{M} \times x$ t.d.s. since 16.10 .17 .

\begin{tabular}{|c|c|c|c|c|c|}
\hline 0.72 & 0.24 & 0.32 & L I. Very slight & L I. Inverted & L I. Very marked \\
\hline 0.70 & $0 \cdot 24$ & 0.32 & & & \\
\hline 0.69 & 0.24 & 0.28 & & & \\
\hline 0.71 & 0.24 & $0 \cdot 32$ & L II. Very slight & L II. Normal & I. II. Very marked \\
\hline 0.71 & $0 \cdot 24$ & 0.32 & & & \\
\hline 0.71 & 0.24 & 0.32 & & & \\
\hline 0.68 & 0.24 & $0 \cdot 32$ & L III. Very slight & L HI. Normal & L III. Not marked \\
\hline 0.70 & 0.24 & 0.32 & & & \\
\hline 0.67 & 0.24 & 0.32 & & & \\
\hline $0 \cdot 64$ & 0.24 & 0.3 & & & \\
\hline 0.64 & 0.24 & $0 \cdot 3$ & & & \\
\hline
\end{tabular}


TABLE III.

Mann. Male, aged 40. Chronic myocarditis - can do but little work.

26.3.18.

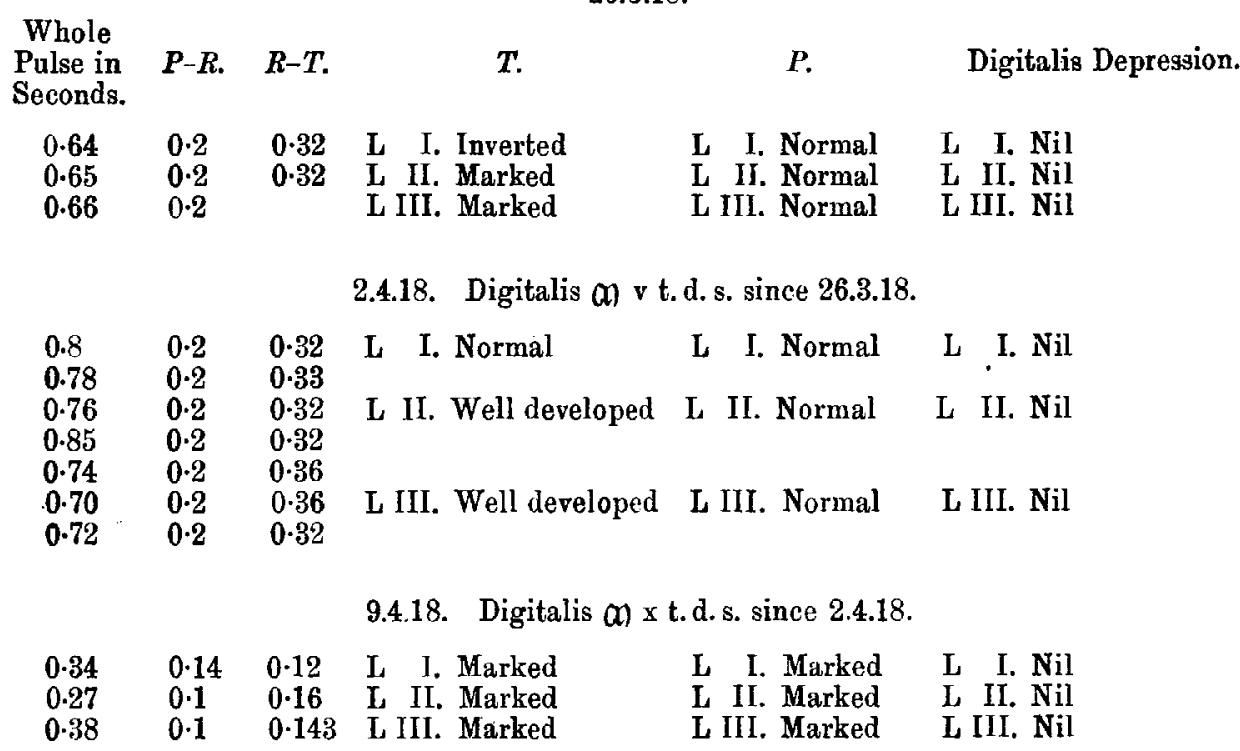

REFERENCES.

1. Cushny, Pharmacology, 7th edit., Lond., 1918.

2. Lewis, Electro-cardiography, Lond., 1912.

3. Cohn, XVIIth International Congress of Medicine, Lond., 1913, Sect. VI, Med. Pt. II. 257.

4. Harris, Lancet, Lond., 1916, i.

5. Lancet, Lond., 1914, i. 910.

\section{EXPLANATION OF FIGURES.}

Plate 2, Figs. 1 and 2, and Plate: 3, Fig. 3 show the gradual development of the digitalis depression.

FIG. 1 was taken before the administration of the digitalis.

Figs. 2 and 3 after the administration of the digitalis.

FIas. 4, 5, and 6 show the influence of digitalis under different phases of the heart-beat.

FIG. 4. Before the administration of digitalis.

FIG. 5. The same patient after digitalis.

FIG. 6 is a typical cardiogram, or the third stage of digitalis. 

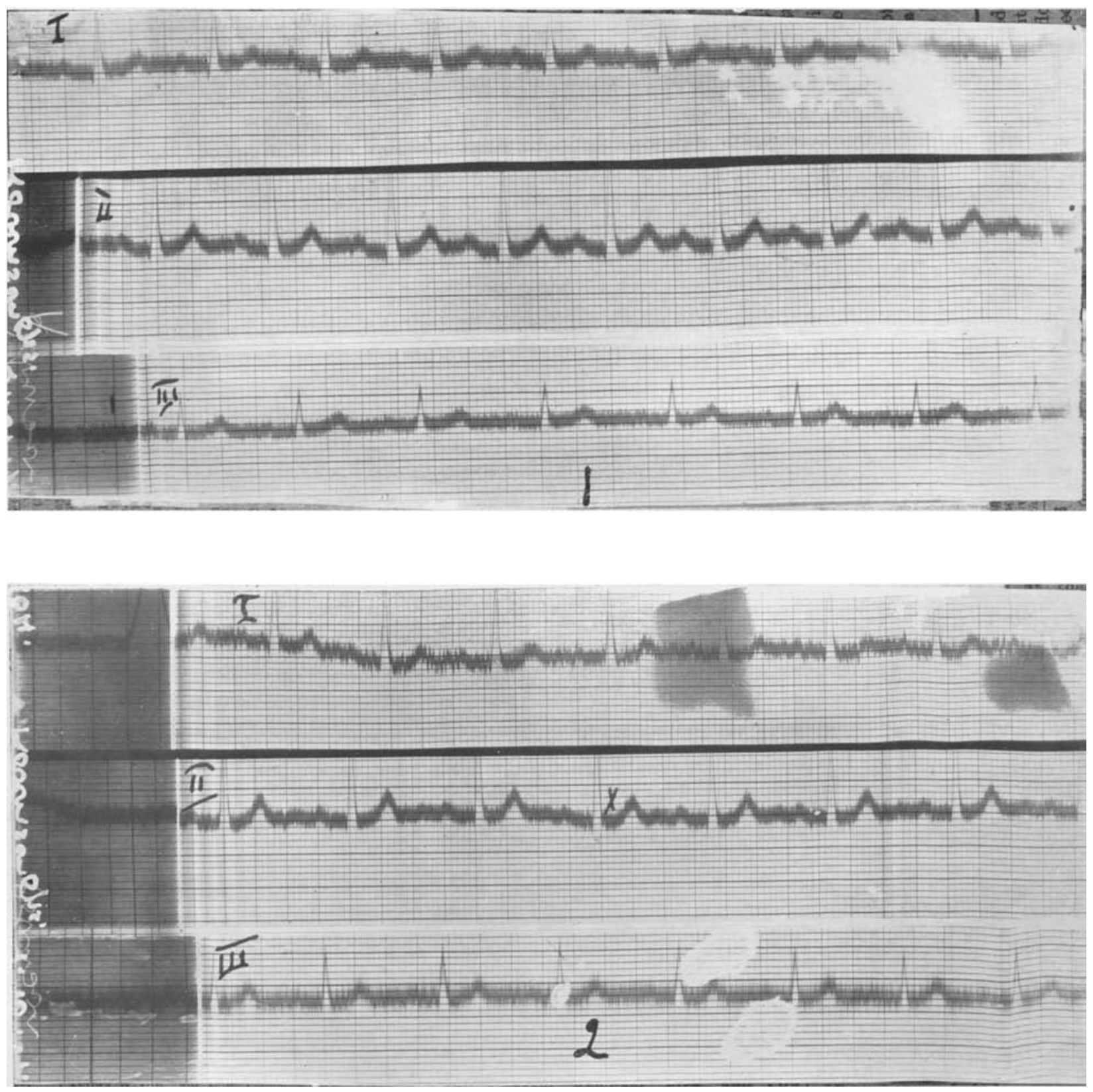

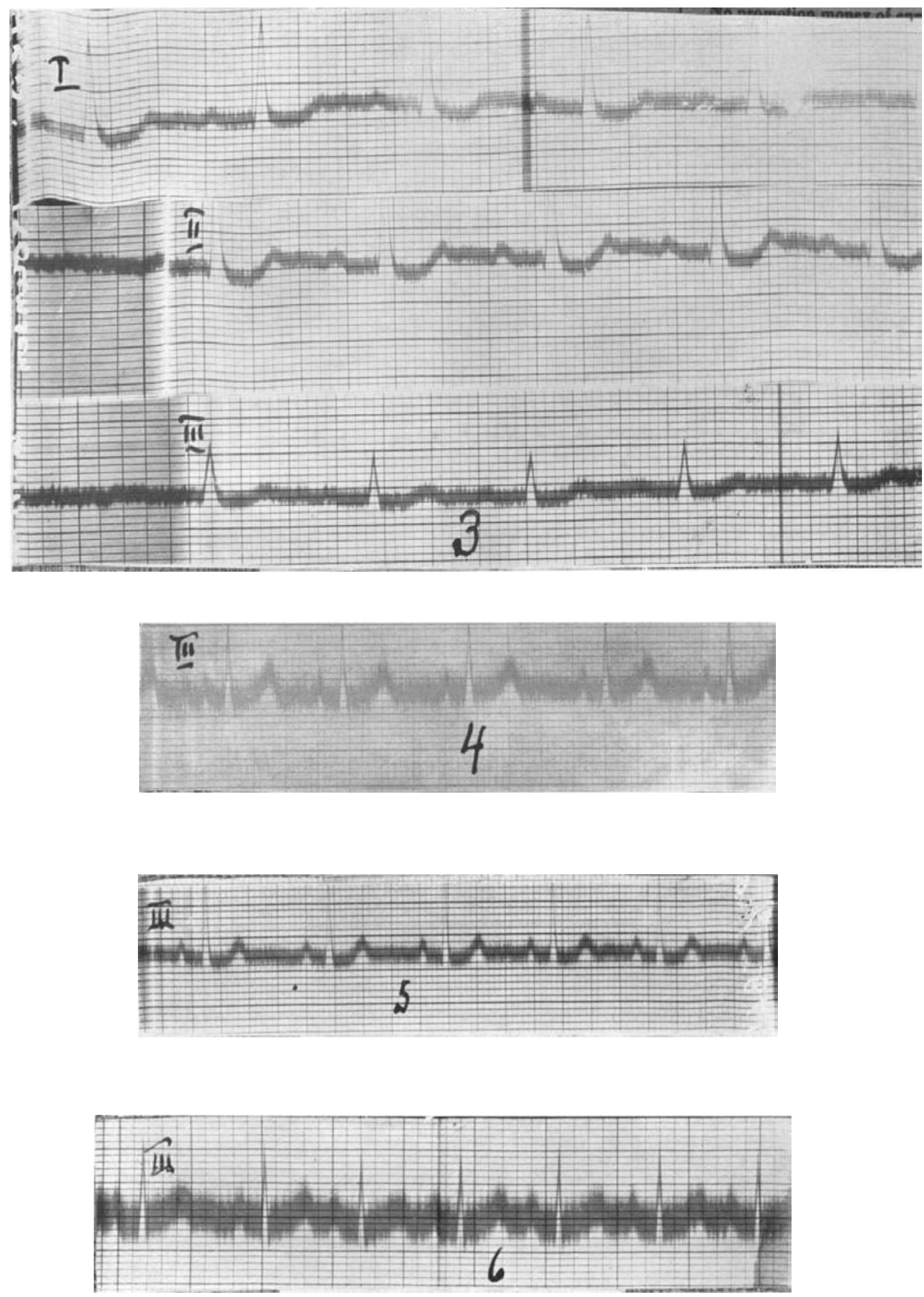